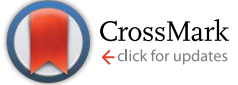

Cite this: RSC Adv., 2015, 5, 33023

Received 19th February 2015

Accepted 24th March 2015

www.rsc.org/advances
DOI: $10.1039 / c 5 r a 03168 k$

\section{Studies on salophen anchored micro/meso porous activated carbon fibres for the removal and recovery of uranium}

\begin{abstract}
Shruti Mishra, ${ }^{\text {ab }}$ Jaya Dwivedi, ${ }^{\text {b }}$ Amar Kumar ${ }^{c}$ and Nalini Sankararamakrishnan*a
Stringent environmental regulations emphasize the removal of uranium from aqueous systems. Activated carbon fibers (ACF) were functionalized by oxidation (ACF-OX) and salophen ligand (ACF-Sal) and evaluated for the removal of uranium. The prepared sorbents were characterized by various techniques such as scanning electron microscopy (SEM), energy dispersive X-ray (EDAX), Fourier transform infrared (FTIR) spectroscopy, Brunauer-Emmett-Teller (BET) surface area analyzer and X-ray photoelectron spectroscopy (XPS). The anchoring of salophen ligand onto ACF surface was evident from the FTIR and XPS studies. The adsorption properties of $\mathrm{UO}_{2}{ }^{2+}$ as a function of $\mathrm{pH}$ and contact time were characterized by inductively coupled mass spectrometry (ICPMS). The adsorption kinetics fitted the pseudo second order kinetics and equilibrium was reached within 180 minutes. The experimental data were modelled with Langmuir and Freundlich isotherms and various isotherm parameters were evaluated. The maximum adsorption capacities of $\mathrm{U}(\mathrm{vI})$ at $\mathrm{pH} 6$ for ACF, ACF-OX and ACF-Sal were found to be 22.2, 50.0 and $142.8 \mathrm{mg} \mathrm{g}^{-1}$, respectively. Thermodynamic studies revealed the spontaneity of the reaction and influence of other cations and anions on the sorption behaviour of uranium has been studied. Studies have been conducted to demonstrate the recyclability of the sorbent for five consecutive sorption desorption cycles. Using FTIR and XPS studies, a suitable mechanism for uranium sorption has also been postulated.
\end{abstract}

\section{Introduction}

Uranium is the second heaviest naturally occurring radioactive element. Uranium is the basic energy element of the present Indian nuclear power programme. It starts as a source of the fuel cycle and finally ends up as a waste component. Uranium is a well-known nephrotoxic heavy metal. It is reported that an exposure of $0.1 \mathrm{mg}$ per $\mathrm{kg}$ body weight of natural $\mathrm{U}$ results in transient chemical damage to the kidneys. ${ }^{1}$ The maximum contaminant level of $\mathrm{U}(\mathrm{VI})$ in water set by the Environmental Protection Agency (EPA) is $30 \mu \mathrm{g} \mathrm{L}^{-1}$, whereas the World Health Organization's guideline value is set at $50 \mu \mathrm{g} \mathrm{\textrm {L } ^ { - 2 }}$. According to the Atomic Energy Research Board (AERB) of India, the maximum allowable concentration of $\mathrm{U}(\mathrm{VI})$ in water bodies is 60 $\mu \mathrm{g} \mathrm{L^{-1 }}$. In aquatic environments, uranium predominantly exists in its hexavalent oxidation state, e.g. $\mathrm{UO}_{2}{ }^{2+}$. These hexavalent uranyl ions are highly mobile and migrate as stable uranyl carbonate complexes under near surface conditions. ${ }^{3}$ Cost effective remediation technology is required to tackle the

${ }^{a}$ Centre for Environmental Science and Engineering, Indian Institute of Technology Kanpur, Kanpur, U.P. 208016, India. E-mail: nalini@iitk.ac.in; Tel: $+91915122596360$

${ }^{b}$ Department of Chemistry, Banasthali Vidyapith, Rajasthan 304022, India

${ }^{\circ}$ Bhabha Atomic Research Centre, Trombay, Mumbai, India removal of uranium from large volumes of wastewater. Several methods, including ion exchange, reduction, reduction followed by chemical precipitation, electrochemical precipitation, membrane separation, solvent extraction, biosorption, and adsorption, are utilized to remove uranium from wastewater and process effluents. Among the various removal technologies for $\mathrm{U}(\mathrm{vI})$ reported, adsorption is the most versatile technique owing to its ease of operation, low waste generation and considerably low recurring cost. The removal of $\mathrm{U}(\mathrm{vI})$ by various adsorbents has been adequately reviewed., ${ }^{4,5}$ Carbon based sorption materials offer various advantages such as higher radiation and thermal resistance than commonly used organic exchange resins and improved chemical stability than widely used inorganic sorbents in strongly acidic solutions in the majority of nuclear wastewaters. ${ }^{4}$ Carbonaceous materials, including activated carbon, ${ }^{6,7}$ activated carbon fibres, carbon nanotubes $^{8-10}$ and mesoporous carbon, ${ }^{11}$ have been reported in the applications of $\mathrm{U}(\mathrm{vI})$ sorption. To improve the selectivity and sorption capacity towards targeted metal ions, functionalization with specific ligands are generally used. ${ }^{4}$ Among these carbonaceous materials, activated carbon fibres (ACF) are unique owing to their large porous surface area, controllable pore structure, thermo-stability and low acid/base reactivity. Furthermore, ACFs are microporous materials possessing high surface area $\left(\sim 1200-1800 \mathrm{~m}^{2} \mathrm{~g}^{-1}\right)$, which is a prime factor for an 
adsorbent. In ACF, micropores which are responsible for adsorption are connected to the external surface directly by narrow diameter fibres $(10-20 \mu \mathrm{m})$. Thus, the diffusion length is small, resulting in negligible mass transfer coefficient and the removal rate of pollutants is adsorption controlled. ${ }^{12}$ ACFs have been found useful for the removal of variety of pollutants like $\mathrm{Cd}(\mathrm{II})$ and $\mathrm{Pb}(\mathrm{II}),{ }^{12-14} \mathrm{Ni}(\mathrm{II})$ and $\mathrm{Zn}(\mathrm{II}),{ }^{15-17} \mathrm{SO}_{2}$, NO and $\mathrm{CO}_{2},{ }^{18}$ and 2-chloroethanol. ${ }^{19}$ Jung et al. ${ }^{20}$ have reported the electrosorption of uranium $(\mathrm{U}(\mathrm{vI}))$ ions onto a porous ACF. However, there are seldom any reports in the literature on the use of functionalized ACFs towards U(vI) removal. It is well known that salophen is a tetradentate ligand that can easily combine with uranyl cation to form a stable uranyl-salophen complex ${ }^{21,22}$ and has been found useful for the determination of trace $\mathrm{U}(\mathrm{vI})$. Thus, this study pertains to the development of functionalized activated carbon fibres by oxidation (ACF-OX), grafting of salophen ligand (ACF-Sal) and its applicability for U(vI) removal. The systematic structural characterization of the functionalized sorbents, namely, ACF-OX and ACF-Sal, were performed using various techniques and optimization of reaction parameters, including $\mathrm{pH}$ and reaction time, were carried out. Isotherm, thermodynamic and kinetic models were evaluated and a suitable mechanism for the adsorption of U(vI) using FTIR and XPS has also been postulated.

\section{Materials and methods}

All the chemicals including, sodium hydroxide $(\mathrm{NaOH})$, nitric acid $\left(\mathrm{HNO}_{3}\right)$, uranyl(vi) nitrate $\left(\mathrm{UO}_{2}\left(\mathrm{NO}_{3}\right)_{2} \cdot 6 \mathrm{H}_{2} \mathrm{O}\right)$, and other reagents and solvents (ethanol, acetone) used in this study were of analytical grade and all the solutions were prepared using Milli-Q purified water (resistivity $>18.2 \mathrm{M} \Omega \mathrm{cm}$ ). 4-Hydroxysalicylaldehyde, thionyl chloride and 1,2-diaminoethane were acquired from Sigma Aldrich chemicals. Activated carbon fibres were purchased from Nippon Kynol In. (Osaka Japan).

\subsection{Preparation of ACF-OX}

Around $1 \mathrm{~g}$ of ACF samples were treated with $20 \mathrm{~mL}$ of $1: 1$ mixture of conc. $\mathrm{HNO}_{3}$ and water and heated at $60{ }^{\circ} \mathrm{C}$ for 30 min, followed by a thorough washing with distilled water and dried in an oven for $12 \mathrm{~h}$ at $120{ }^{\circ} \mathrm{C}$.

\subsection{Preparation of salophen ligand}

A stoichiometric amount of 4-hydroxysalicylaldehyde $(0.02 \mathrm{~mol}$, $2.76 \mathrm{~g})$ in dissolved methanol $(25 \mathrm{~mL})$ was added dropwise to 1,2-diaminoethane solution ( $0.01 \mathrm{~mol}, 0.60 \mathrm{~g})$ in $25 \mathrm{~mL}$ methanol. The contents were refluxed for $4 \mathrm{~h}$ and a bright yellow precipitate of symmetrical Schiff-base ligand, $\mathrm{H}_{2}\left[(\mathrm{OH})_{2}-\right.$ salen], was obtained.<smiles>NCCNCC(N)C=O</smiles>

2,4-Dihydroxybenzaldehyde Ethylenediamine<smiles>Oc1ccc(C=NCCN=Cc2ccc(O)cc2O)c(O)c1</smiles>

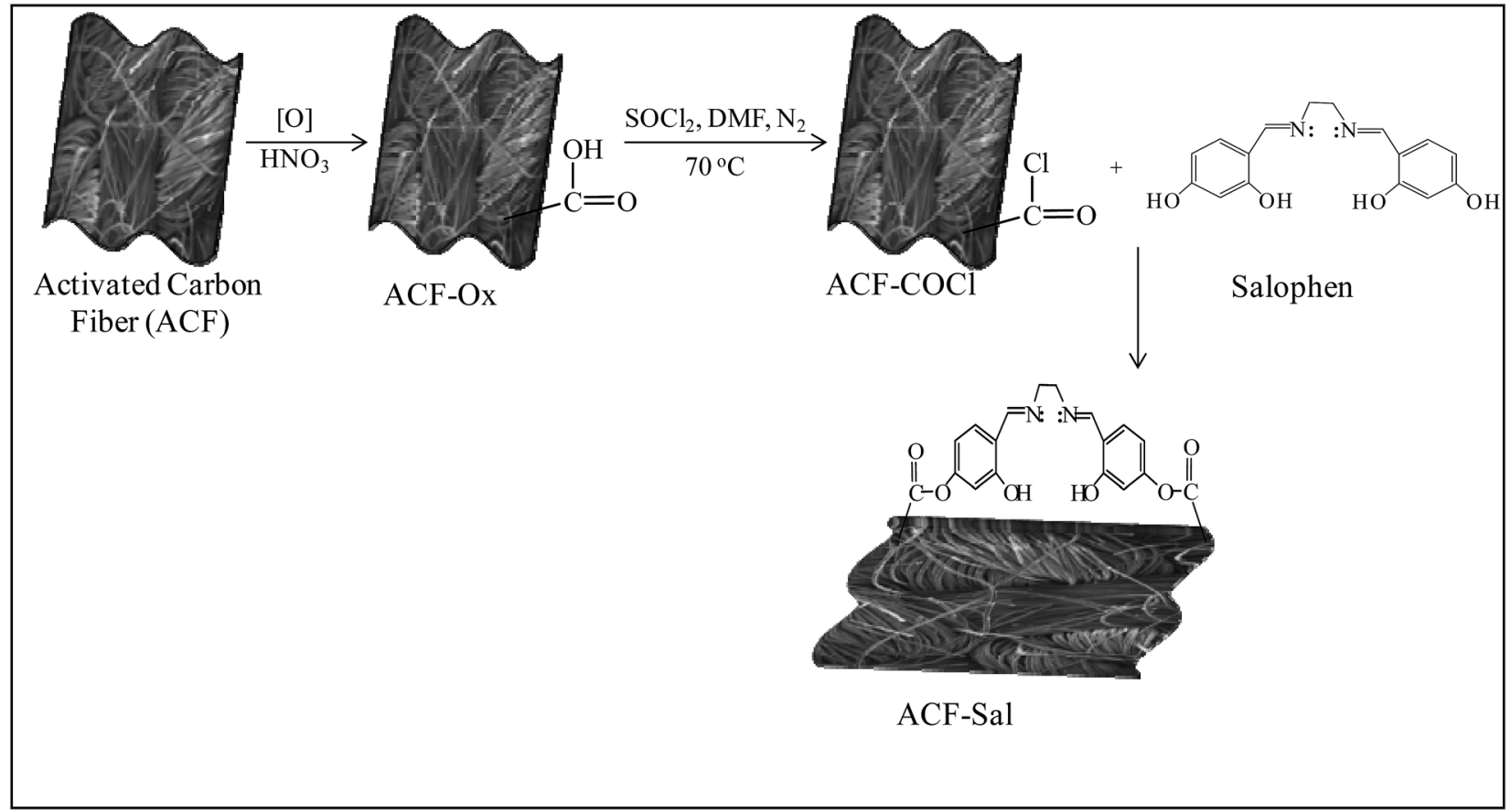

Scheme 1 Schematic representation of ACF functionalization. 


\subsection{Preparation of ACF-Sal}

Initially, chlorinated ACFs were prepared. Around $100 \mathrm{mg}$ of ACFs were suspended in a solution of $\mathrm{SOCl}_{2}(25 \mathrm{~mL})$ and DMF $(1 \mathrm{~mL})$. The suspension was stirred at $65^{\circ} \mathrm{C}$ for $24 \mathrm{~h}$. The solid was then separated by filtration, washed with anhydrous THF, and dried in vacuum. To a solution of salophen $(100 \mathrm{mg})$ in degassed $\mathrm{CHCl}_{3}(8 \mathrm{~mL})$, chlorinated ACFs were added $(50 \mathrm{mg})$ and the suspension was stirred for $20 \mathrm{~h}$ under $\mathrm{N}_{2}$ atmosphere at $70{ }^{\circ} \mathrm{C}$. The solid was then separated by filtration, exhaustively washed with THF and $\mathrm{CH}_{2} \mathrm{Cl}_{2}$, and dried under vacuum. The schematic of the preparation of ACF-OX and ACF-Sal is shown in Scheme $1 .^{23}$

\subsection{Batch studies}

Adsorption experiments were carried out by a batch technique. About $0.05 \mathrm{~g}$ of adsorbent was placed in a beaker containing 20 $\mathrm{mL}$ of 0.1 to $500 \mathrm{mg} \mathrm{L}^{-1}$ of $\mathrm{U}(\mathrm{vI})$ solution for ACF and ACF-OX and 0.1 to $1000 \mathrm{mg} \mathrm{L}^{-1}$ for ACF-Sal. The $\mathrm{pH}$ of the solution was adjusted to 6.0 by adding $10 \%$ sodium hydroxide or $10 \%$ sulphuric acid solutions. The suspension was stirred for $3 \mathrm{~h}$ at an agitation speed of $110 \mathrm{rpm}$. At the end of the equilibrium time, the content was separated by filtration with a $0.22 \mu \mathrm{m}$ pore size filter paper and U(vI) in solution was analyzed by inductively coupled plasma-mass spectrometry (ICP-MS) (Thermo Scientific, XSERIES 2). All the experiments were repeated twice. The
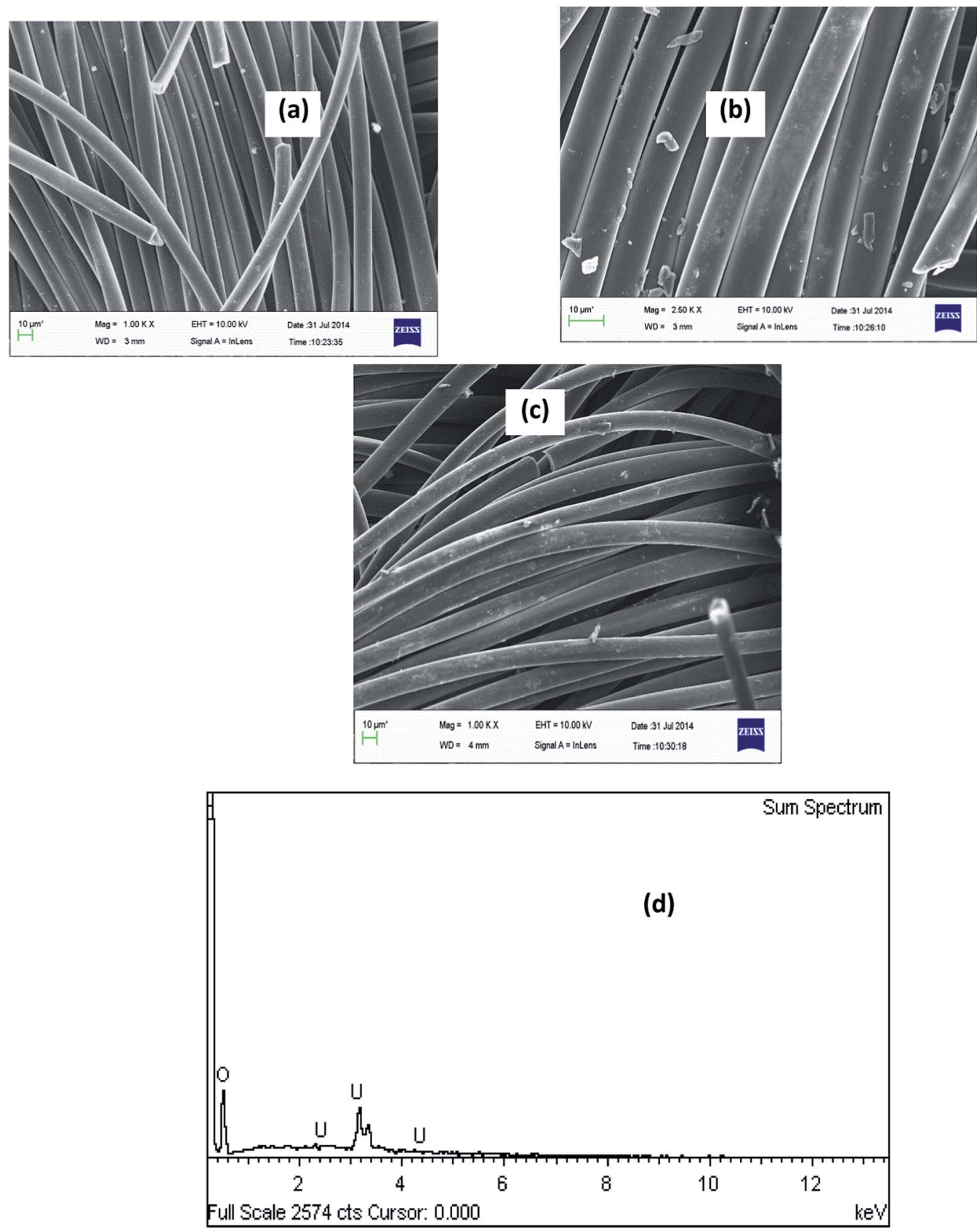

Fig. 1 SEM images of (a) pristine ACF, (b) ACF-OX, (c) ACF-Sal, and (d) EDAX spectra of ACF-Sal-U. 
amount of the $\mathrm{U}(\mathrm{vI})$ adsorbed (mg) per unit mass of sorbent $(\mathrm{g})$, $q_{\mathrm{e}}$, was obtained by mass balance using the following equation:

$$
q_{\mathrm{e}}=\frac{\left(C_{\mathrm{i}}-C_{\mathrm{e}}\right)}{m} \times V
$$

where $C_{\mathrm{i}}$ and $C_{\mathrm{e}}$ are initial and equilibrium concentrations of the $\mathrm{U}(\mathrm{vI})\left(\mathrm{mg} \mathrm{L}^{-1}\right), m$ is dry mass of sorbent $(\mathrm{g})$ and $V$ is the volume of the solution $(\mathrm{L})$. Kinetic experiments were conducted by equilibrating $20 \mathrm{~mL}$ of $100 \mathrm{mg} \mathrm{L}^{-1}$ of $\mathrm{U}(\mathrm{vI})$ at a dose rate of 5.0 $\mathrm{g} \mathrm{L}^{-1}$ and the $\mathrm{pH}$ was maintained at 6.0 during equilibration. The amount of uranium adsorbed was monitored at regular time intervals. The effect of competing cations and anions were examined by maintaining the initial concentration of uranium at $100 \mathrm{mg} \mathrm{L}^{-1}$. Using the same conditions mentioned above, thermodynamic studies were carried out by equilibrating the solutions for $3 \mathrm{~h}$ at three different temperatures at $25{ }^{\circ} \mathrm{C}, 35^{\circ} \mathrm{C}$ and $45{ }^{\circ} \mathrm{C}$ and the amount of uranium adsorbed was determined. Recyclability studies were performed using $0.1 \mathrm{M} \mathrm{H}_{3} \mathrm{PO}_{4}$ as the desorbent. After each cycle, the adsorbent was filtered and equilibrated with $20 \mathrm{ml}$ of $0.1 \mathrm{M} \mathrm{H}_{3} \mathrm{PO}_{4}$ for $30 \mathrm{~min}$ and the adsorbent was filtered, thoroughly washed with water and used for the consequent adsorption cycle.

\subsection{Analytical measurements}

Fourier transform infrared (FTIR) measurements were made with $\mathrm{KBr}$ pellets using a Tensor 27 (Bruker, Germany) in the attenuated total reflectance (ATR) mode. A FEI Quanta 200 machine was used for scanning electron microscopy (SEM). XPS measurements were performed using a PHI 5000 Versa Prob II (FEI Inc.) spectrometer using nonmonochromatic Al K $\alpha$ radiation (1486.6 eV). XPSPEAK41 software with a Gaussian-Lorentzian line shape was used for the deconvolution of individual spectral peaks. A nonlinear Shirley background subtraction was applied for fitting each spectral region. The adsorbent was analyzed for the pore size distribution (PSD), specific surface area and pore volume by $\mathrm{N}_{2}$-physisorption using a Autosorb-1C instrument (Quantachrome, USA). Uranyl ions concentrations were determined by

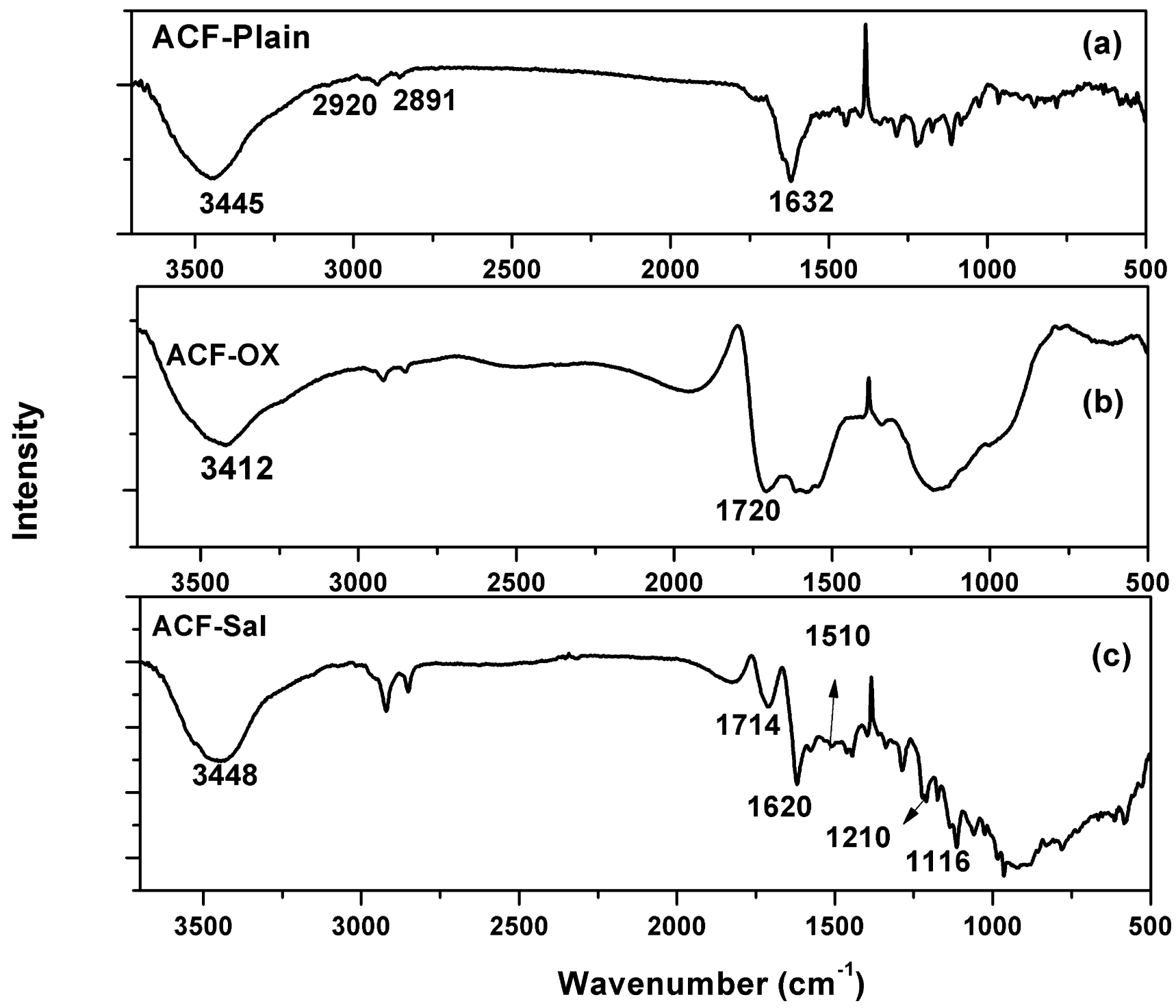

Fig. 2 FTIR spectra of (a) plain ACF (b) ACF-OX and (c) ACF-Sal. 
Table 1 Surface area and pore volumes of virgin and functionalized ACF

\begin{tabular}{llllr}
\hline Adsorbent & $\begin{array}{l}\text { Surface area } \\
\left(\mathrm{m}^{2} \mathrm{~g}^{-1}\right)\end{array}$ & $\begin{array}{l}\text { Average diameter } \\
(\mathrm{nm})\end{array}$ & $\begin{array}{l}\text { Total pore volume } \\
\left(\mathrm{cc} \mathrm{g}^{-1}\right)\end{array}$ & $\begin{array}{r}\text { Pore volume }\left(\mathrm{cc} \mathrm{g}^{-1}\right) \\
\text { Meso }\end{array}$ \\
\hline ACF & 1337.0 & 2.10 & 0.7020 & 0.031 \\
ACF-OX & 1416.5 & 0.95 & 0.6737 & 0.033 \\
ACF-Sal & 1410.0 & 0.98 & 0.6800 & 0.6407 \\
& & & & 0.6480
\end{tabular}

Inductive coupled plasma mass spectroscopy ICP-MS (Thermo, XSeries2). Calibration was carried out daily with freshly prepared uranium standards before sample analysis.

\section{Results and discussion}

\subsection{Characterization of adsorbent}

3.1.1 SEM analysis. SEM images of ACF, oxidized ACF, and ACF-Sal are shown in Fig. 1a-c, respectively. ACF are composed of bundles of fibres with a diameter of about $10 \mu \mathrm{m}$. It is evident from the images that the surfaces of pristine ACF, ACF-OX and ACF-Sal are found to be smooth. The loading of uranium on ACF-Sal was confirmed from the Energy Dispersive X-ray analysis (EDAX), as shown in Fig. 1 d.

3.1.2 FTIR spectra. FTIR spectra from the ACFs show a broad peak at $\sim 3445 \mathrm{~cm}^{-1}$, which is a characteristic of the $\mathrm{O}-\mathrm{H}$ stretch of the hydroxyl group (Fig. 2a), arising from the oscillation of carboxyl groups. The peaks at 2891 and $2920 \mathrm{~cm}^{-1}$ correspond to $-\mathrm{CH}_{2}$ and $-\mathrm{CH}$ symmetric stretch, respectively. The $\mathrm{C}=\mathrm{C}$ stretching vibration was found at $1632 \mathrm{~cm}^{-1}$. An additional peak at $1720 \mathrm{~cm}^{-1}$ corresponding to $\mathrm{C}=\mathrm{O}$ stretching was found after the oxidation of ACF with nitric acid (ACF-OX) (Fig. 2b). ${ }^{24}$ In the salophen anchored ACF (Fig. 2c), the peaks at 1510 and $1620 \mathrm{~cm}^{-1}$ are attributed to the absorption of carbon-nitrogen double bond of the azomethine group. ${ }^{23}$ Furthermore, additional peaks at $1210 \mathrm{~cm}^{-1}$ and $1116 \mathrm{~cm}^{-1}$ are due to the $\mathrm{C}-\mathrm{O}$ and $\mathrm{C}-\mathrm{N}$ stretching vibration, respectively. ${ }^{21}$

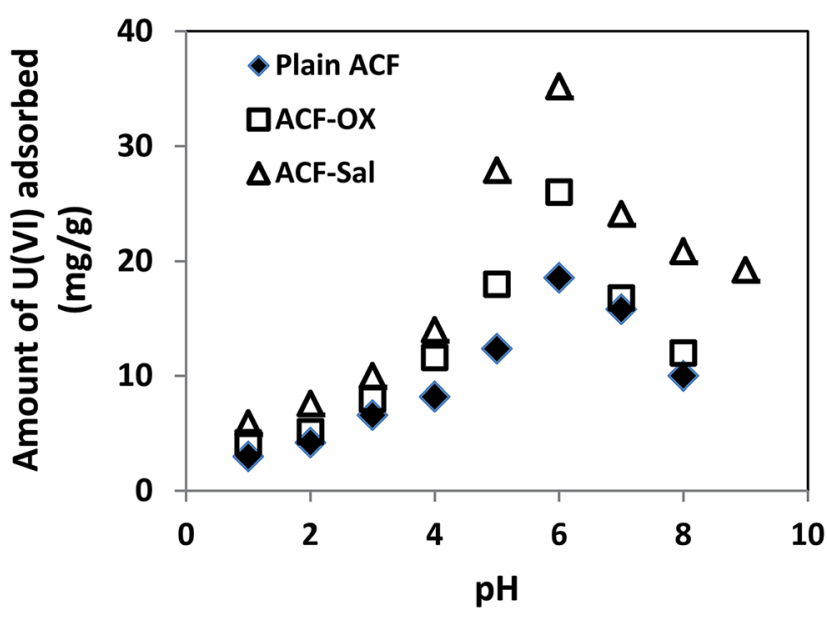

Fig. 3 Effect of initial $\mathrm{pH}$ on ACF, ACF-OX and ACF-Sal with $U(\mathrm{VI})$.
3.1.3 BET measurements. The specific surface area of ACF, ACF-OX and ACF-Sal was obtained over the relative pressure range from 0.05 to 0.35 using the standard BET method. The total pore, mesopore and micropore volumes were calculated using the instrument's software supplied by Quantachrome using Barrett-Joyner-Halenda (BJH) and density functional theory (DFT) methods. Table 1 summarizes the data for BET surface area and pore volumes of various ACFs. The large surface area and small pore size of these materials lead to the strong confinement of the adsorbed phase, together with strong interactions with the surface. It is evident that the surface area of the ACFs increased from $1337 \mathrm{~m}^{2} \mathrm{~g}^{-1}$ to $1416.5 \mathrm{~m}^{2} \mathrm{~g}^{-1}$ upon oxidation with nitric acid and further grafting with salophen ligand does not affect the surface area of the sorbent. During oxidation, the increased surface area could be attributed to the opening of pores. The marginal decrease in pore volumes of functionalized ACFs could be attributed to the blockage of interbundle galleries and intra-bundle interstitial channels by various functional groups.

\subsection{Effect of initial $\mathrm{pH}$}

The effect of the variation of initial $\mathrm{pH}$ in the range of 1-9 on adsorption using ACF, ACF-OX and ACF-Sal was examined. The initial concentration of $\mathrm{U}(\mathrm{vI})$ was maintained at $100 \mathrm{mg} \mathrm{L}^{-1}$. Efforts were made not to maintain the $\mathrm{pH}$ throughout the sorption experiments. The results obtained are shown in Fig. 3. It is evident from the figure that the sorption of $\mathrm{U}(\mathrm{vI})$ increased greatly from $\mathrm{pH} 4$ to $\mathrm{pH} 6$ and further increases in $\mathrm{pH}$ resulted in decreased sorption. At $\mathrm{pH} \leq 3, \mathrm{UO}_{2}{ }^{2+}$ is the predominant species of ions and sorption is found to be very low owing to the competition of $\mathrm{H}^{+}$ions for the active binding sites of the sorbent. ${ }^{9}$ In the $\mathrm{pH}$ range of 5.5-7.5, the hydrolysis of uranyl ions occurs and various multinuclear hydroxyl complexes are prevalent, including $\mathrm{UO}_{2}(\mathrm{OH})^{+}, \quad\left(\mathrm{UO}_{2}\right)_{2}(\mathrm{OH})_{2}{ }^{2+}$ and $\left(\mathrm{UO}_{2}\right)_{3}(\mathrm{OH})_{5}{ }^{+} \cdot{ }^{25}$ Thus, the maximum adsorption of $\mathrm{U}(\mathrm{vI})$ was found at $\mathrm{pH} 6$. At $\mathrm{pH}$ values greater than 7 , anionic $\mathrm{U}(\mathrm{vI})$ species $\left(\mathrm{UO}_{2}\right)_{3}(\mathrm{OH})_{7}{ }^{-}$were prevalent, which resulted in low sorption capacity. ${ }^{26}$ Furthermore, the amount of $\mathrm{U}(\mathrm{vI})$ increased from $18.56 \mathrm{mg} \mathrm{g}^{-1}$ to $35.2 \mathrm{mg} \mathrm{g}^{-1}$ after functionalization with salophen ligand. This can be explained by the complexation of $\mathrm{U}(\mathrm{vI})$ and salophen ligand, which are detailed in section 3.9.

\subsection{Effect of contact time}

Sorption of $\mathrm{U}(\mathrm{vI})$ on ACF-Sal as a function of contact time was carried out at $\mathrm{pH} 6.0 \pm 0.1$. The results obtained are shown in Fig. 4a. The sorption of U(vI) on ACF-Sal was shown to be rapid and 

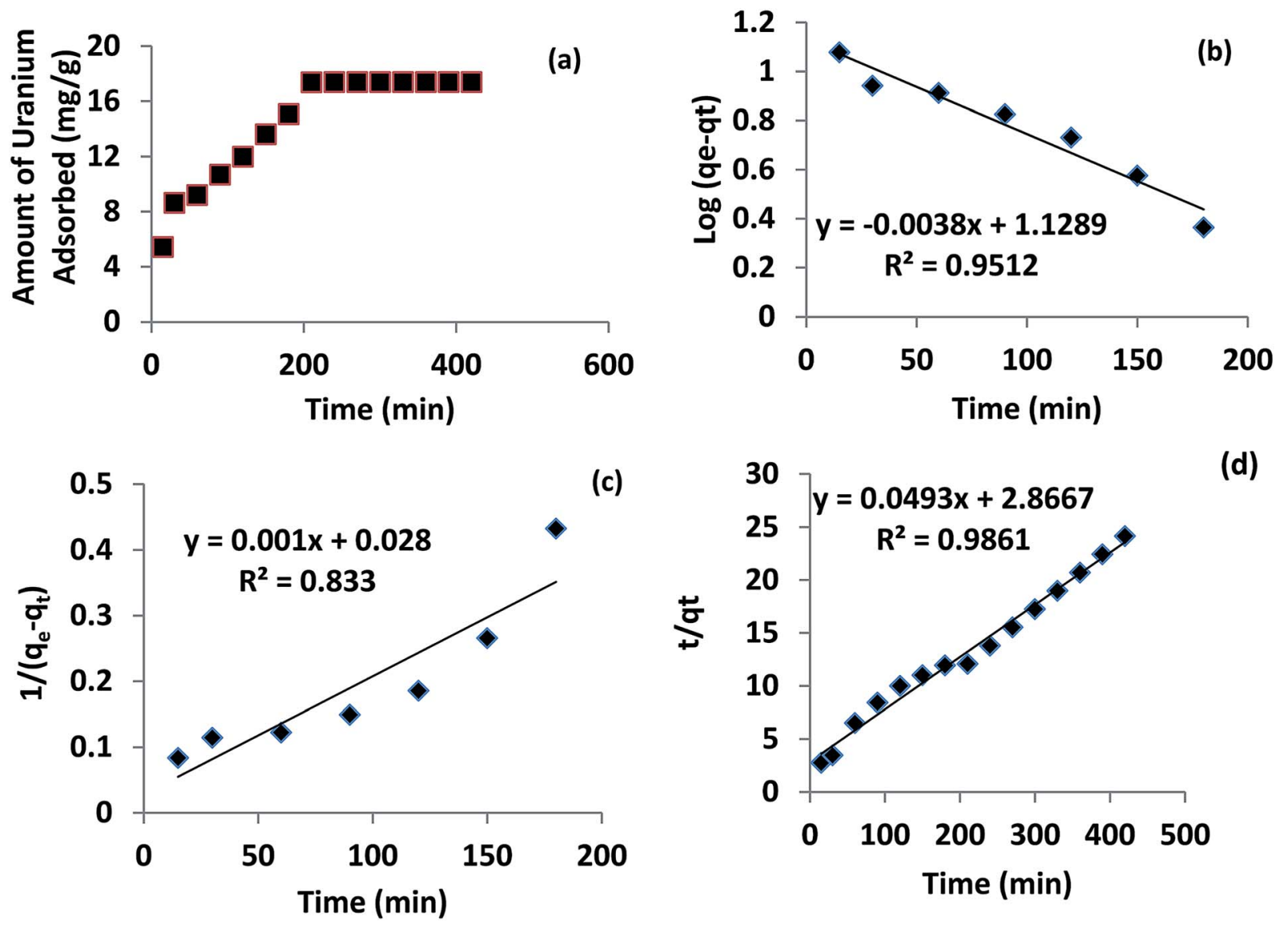

(d)

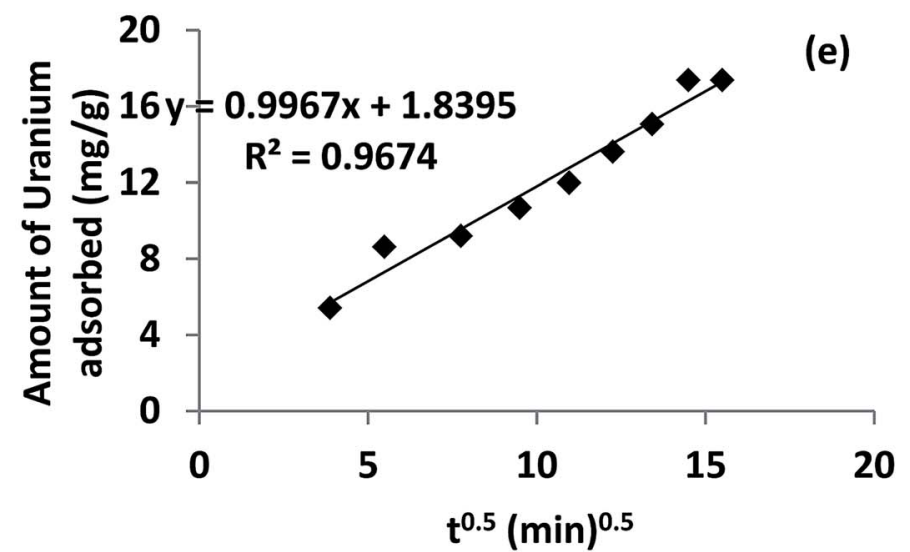

Fig. 4 (a) Effect of equilibration time, (b) pseudo first order kinetic model, (c) second order kinetic model, (d) pseudo second order kinetic model, and (e) Web-Morris model of ACF-Sal and uranium system.

Table 2 Kinetic parameters of ACF-Sal and U(VI) systems

\begin{tabular}{llllll}
\hline \multicolumn{2}{l}{ Pseudo first order } & \multicolumn{2}{l}{ Second order } & & \multicolumn{2}{c}{ Pseudo second order } \\
\hline$k_{1}\left(\mathrm{~min}^{-1}\right)$ & $R^{2}$ & $\begin{array}{l}k_{2} \\
\left(\mathrm{mg} \mathrm{g}^{-1} \mathrm{~min}^{-1}\right)\end{array}$ & $R^{2}$ & $k_{2}^{\prime}$ & $R^{2}$ \\
0.0069 & 0.951 & 0.001 & 0.833 & 0.0007 & 0.986
\end{tabular}

a contact time of $3.5 \mathrm{~h}$ was enough to reach sorption equilibrium. Thus, all the experiments were carried out at $4 \mathrm{~h}$ equilibration time. The kinetics of $\mathrm{U}(\mathrm{vI})$ adsorption onto ACF-Sal was modelled using the Lagergren model ${ }^{27}$ or pseudo first order, second order ${ }^{28}$ and pseudo second order, ${ }^{29}$ as shown in eqn (2)-(4), respectively.

$$
\log \left(q_{\mathrm{e}}-q_{t}\right)=\log q_{\mathrm{e}}-\frac{k_{\mathrm{l}}}{2.303} t
$$

$$
\frac{1}{q_{\mathrm{e}}-q_{t}}=\frac{1}{q_{\mathrm{e}}}+k_{2} t
$$




$$
\frac{t}{q_{t}}=\frac{1}{k_{2}^{\prime} q_{\mathrm{e}}^{2}}+\frac{t}{q_{\mathrm{e}}}
$$

where $k_{\mathrm{L}}$ is the Lagergren rate constant of adsorption $\left(\mathrm{min}^{-1}\right)$; $k_{2}$ the second-order rate $\left(\mathrm{g} \mathrm{mg}^{-1} \mathrm{~min}^{-1}\right)$ and $k_{2}^{\prime}$ the pseudosecond-order rate constant of adsorption $\left(\mathrm{g} \mathrm{mg}^{-1} \mathrm{~min}^{-1}\right) ; q_{\mathrm{e}}$ and $q_{t}$ are the amounts of $\mathrm{U}(\mathrm{vI})$ ion $\left(\mathrm{mg} \mathrm{g}^{-1}\right)$ at equilibrium and at time $t$, respectively. The plots of various models are depicted in Fig. 4b-d. The rate constants obtained for various kinetic models are given in Table 2. It is evident that among the pseudo first order, second order and pseudo second order plots, the pseudo second order plot of $t / q_{t} v s$. $t$, Fig. $4 \mathrm{c}$, yielded a straight line with correlation coefficients of $>0.98$. Thus, it could be concluded that the sorption of $\mathrm{U}(\mathrm{vI})$ with ACF-Sal followed pseudo second order kinetics. Since this model is based on the assumption that the rate-limiting step may be chemical sorption, involving valency forces through sharing or exchange of electrons between sorbent and analyte, it is postulated that complex formation between the salophen ligand and $\mathrm{U}(\mathrm{vI})$ ions is the rate limiting step for the sorption of U(Iv) onto ACF-Sal.

It is generally known that a typical solid/liquid sorption involves film diffusion or intraparticle diffusion as well. The probability of intraparticle diffusion could be modelled by the Weber and Morris model ${ }^{30}$ and this model relates the amount of the $\mathrm{U}(\mathrm{vI})$ adsorbed and the intraparticle rate constant $\left(k_{\mathrm{int}}\right)$ given by eqn (5)

$$
q_{t}=k_{\text {int }} \sqrt{t}+C
$$

The plot of $q_{t}$ against $\sqrt{ } t$ results in an intercept (Fig. 4e). If the intraparticle diffusion is the sole rate determining step, then the plot of $q_{t} v s$. $\sqrt{ } t$ should pass through the origin with zero intercept. However, in the present scenario (Fig. 4e), $q_{t} v s$. $\sqrt{ } t$ does not pass through the origin. Hence, we can conclude that intraparticle diffusion is not the sole rate determining step for the sorption of $\mathrm{U}(\mathrm{vI})$ on ACF-Sal. The value of intraparticle diffusion constant $\left(k_{\mathrm{int}}\right)$ of $\mathrm{U}(\mathrm{vI})$ was found to be $1.021\left(\mathrm{~g} \mathrm{mg}^{-1}\right)$ $\left(\min ^{0.5}\right)^{-1}$.

\subsection{Sorption isotherms}

The U(vI) adsorption isotherms for ACF, ACF-OX, and ACF-Sal are presented in Fig. 5a. The adsorption data of $\mathrm{U}(\mathrm{vI})$ over various functionalized ACFs were modelled using various isotherms. The most commonly used Langmuir model describes the formation of homogeneous monolayer on the sorbent surface. The adsorption of $\mathrm{U}(\mathrm{vI})$ ions from the bulk to functionalized ACF surface could be expressed by Langmuir expression $^{31}$ as follows:
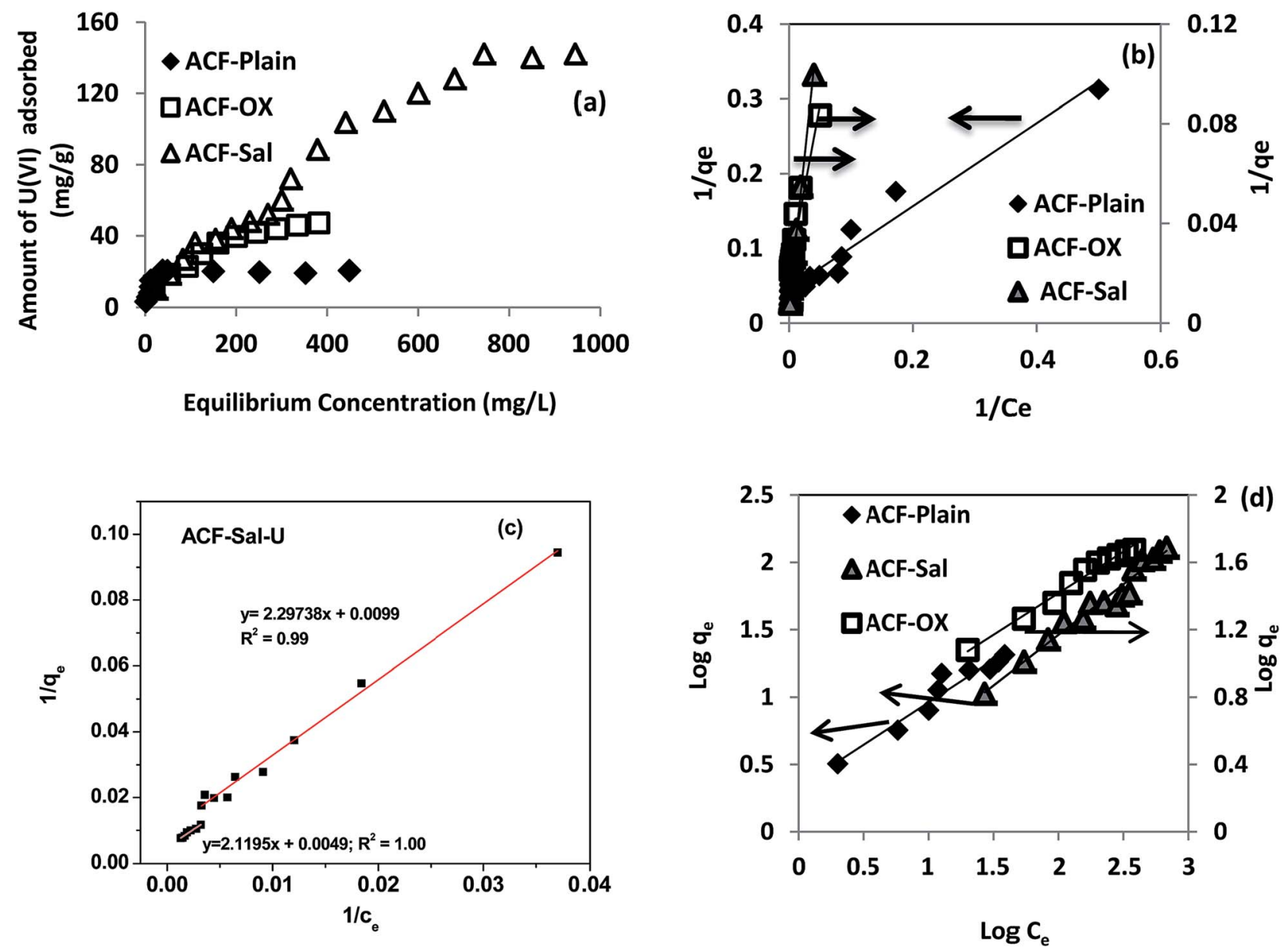

Fig. 5 (a) Equilibrium isotherm, (b) linearized Langmuir plot, (c) two site Langmuir plot, (d) Freundlich plot. 
Table 3 Isotherm parameters of ACF, ACF-OX and ACF-Sal with U(VI) systems

\begin{tabular}{|c|c|c|c|c|c|c|c|c|c|c|}
\hline \multirow[b]{2}{*}{ Adsorbent } & \multicolumn{3}{|c|}{ Langmuir model } & \multicolumn{6}{|c|}{ Two site Langmuir model } & \multirow{2}{*}{$\begin{array}{l}\begin{array}{l}\text { Freundlich } \\
\text { model }\end{array} \\
K_{\mathrm{F}} \\
\left(\mathrm{L} \mathrm{g}^{-1}\right)\end{array}$} \\
\hline & $\begin{array}{l}q_{\max } \\
\left(\mathrm{mg} \mathrm{g}^{-1}\right)\end{array}$ & $\begin{array}{l}b \\
\left(\mathrm{~L} \mathrm{mg}^{-1}\right)\end{array}$ & $R^{2}$ & $\begin{array}{l}q_{\mathrm{m}}^{\prime} \\
\left(\mathrm{mg} \mathrm{g^{-1 }}\right)\end{array}$ & $\begin{array}{l}b^{\prime} \\
\left(\mathrm{L} \mathrm{mg}^{-1}\right)\end{array}$ & $R^{2}$ & $\begin{array}{l}q_{\mathrm{m}}^{\prime \prime} \\
\left(\mathrm{mg} \mathrm{g}^{-1}\right)\end{array}$ & $\begin{array}{l}b^{\prime \prime} \\
\left(\mathrm{L} \mathrm{mg}^{-1}\right)\end{array}$ & $R^{2}$ & \\
\hline $\mathrm{ACF}$ & 22.22 & 0.8640 & 0.96 & - & - & - & - & - & - & 2.673 \\
\hline ACF-OX & 50.00 & 0.0149 & 0.94 & - & - & - & - & - & - & 2.138 \\
\hline ACF-Sal & 142.86 & 0.0029 & 0.99 & 204.08 & 0.0023 & 1.00 & 101.01 & 0.0043 & 0.99 & 0.916 \\
\hline
\end{tabular}

$$
q_{\mathrm{e}}=\frac{q_{\mathrm{m}} b C_{\mathrm{e}}}{1+b C_{\mathrm{e}}}
$$

where $q_{\mathrm{e}}$ is the amount of $\mathrm{U}(\mathrm{vI})$ adsorbed $\left(\mathrm{mg} \mathrm{g}^{-1}\right)$ at equilibrium and $C_{\mathrm{e}}$ is the equilibrium concentration $\left(\mathrm{mg} \mathrm{L}^{-1}\right)$. The empirical constants $q_{\mathrm{m}}$ and $b$ denote the maximum adsorption capacity and energy of adsorption, respectively, and were calculated from the slope and intercept of plot between $1 / C_{\mathrm{e}}$ and $1 / q_{\mathrm{e}}$ (Fig. 5b). The constant ' $b$ ' is attributed to the affinity between the adsorbent and analyte in the given system. The values obtained for the various constants are given in Table 3. It is evident from Fig. 5a that an "S-isotherm" curve was obtained using ACF-Sal as an adsorbent. The curve obtained is sigmoidal with a point of deflection. At low $\mathrm{U}(\mathrm{vI})$ concentrations, the adsorption is limited by the presence of the salophen ligand. After the complexation of $\mathrm{U}(\mathrm{vI})$ with the salophen ligand, normal adsorption occurs. ${ }^{32}$ The point of inflection illustrates the concentration, for which the other process of sorption overcomes the complexation. To further explain this behaviour, the data obtained was modelled by the two site Langmuir isotherm, ${ }^{33}$ given by eqn (7).

$$
q_{\mathrm{e}}=\frac{q_{\mathrm{m}}^{\prime} b^{\prime} C_{\mathrm{e}}}{1+b^{\prime} C_{\mathrm{e}}}+\frac{q_{\mathrm{m}}^{\prime \prime} b^{\prime \prime} C_{\mathrm{e}}}{1+b^{\prime \prime} C_{\mathrm{e}}}
$$

The two-site Langmuir isotherms fit the adsorption data well when there are two types of adsorption sites with different binding energies on the adsorbents. ${ }^{33} q_{\mathrm{m}}^{\prime}\left(\mathrm{mg} \mathrm{g}^{-1}\right)$ and $q_{\mathrm{m}}^{\prime \prime}(\mathrm{mg}$ $\left.\mathrm{g}^{-1}\right)$ are the maximum absorption capacities and $b 1\left(\mathrm{~L} \mathrm{mg}^{-1}\right)$ and $b 2\left(\mathrm{~L} \mathrm{mg}^{-1}\right)$ in eqn (7) are the affinity coefficients to sites 1 and 2 on the adsorbents, respectively. The total maximum adsorption capacity can be obtained by adding $q_{\mathrm{m}}^{\prime}$ and $q_{\mathrm{m}}^{\prime \prime}$. It is evident from the data that the maximum adsorption capacity of the three sorbents towards U(vI) is in the order ACF-Sal > ACFOX > ACF. It is evident that the sorption capacity of ACF-Sal from the two site Langmuir model is 13.68 times higher than plain ACF. The high sorption capacity of ACF-Sal towards U(vI) could be attributed to the complex formation between salophen ligand and $\mathrm{U}(\mathrm{vI})$ ions. The adsorption capacity of ACF-Sal is significantly higher than the adsorption capacity of various carbon adsorbents such as plain oxidized MWCNT ${ }^{26}(43.32 \mathrm{mg}$ $\left.\mathrm{g}^{-1}\right)$, carboxymethyl cellulose grafted $\mathrm{CNT}^{34}\left(112.0 \mathrm{mg} \mathrm{g}^{-1}\right)$, diglycolamide functionalized MWCNTs ${ }^{35}\left(133.7 \mathrm{mg} \mathrm{g}^{-1}\right)$, palm shell activated carbon ${ }^{36}\left(51.81 \mathrm{mg} \mathrm{g}^{-1}\right)$ and imine functionalized carbon spheres $^{37}\left(113 \mathrm{mg} \mathrm{g}^{-1}\right)$.
Further analysis of the Langmuir model could be achieved based on a dimensionless equilibrium parameter called separation factor $\left(R_{\mathrm{L}}\right):^{38}$

$$
R_{\mathrm{L}}=\frac{1}{1+b C_{0}}
$$

where $C_{0}$ is the initial concentration of $\mathrm{U}(\mathrm{vI})$ and ' $b$ ' is the Langmuir adsorption equilibrium constant $\left(\mathrm{mL} \mathrm{mg}^{-1}\right)$. The value of $R_{\mathrm{L}}$ indicates that the isotherm represents a favourable $\left(0<R_{\mathrm{L}}<1\right)$, unfavourable $\left(R_{\mathrm{L}}<1\right)$, linear $\left(R_{\mathrm{L}}=1\right)$, or irreversible process $\left(R_{\mathrm{L}}=0\right)$. For an initial concentration of $100 \mathrm{mg} \mathrm{L}^{-1}$, the $\mathrm{U}(\mathrm{vI}) R_{\mathrm{L}}$ values for ACF, ACF-OX and ACF-Sal were found to be $0.0115,0.4016$, and 0.7752 , respectively. These values suggest that the adsorption of uranyl ions by ACF and functionalized ACFs is a favourable process.

The heterogeneity of the system is described by the Freundlich model and its linearized form is represented below ${ }^{39}$

$$
\log q_{\mathrm{e}}=\frac{1}{n} \log C_{\mathrm{e}}+\log K_{\mathrm{f}}
$$

Fig. 5d denotes the Freundlich plots of various sorbents. $n$ and $K_{\mathrm{f}}$ are the Freundlich parameters, which represent the adsorption capacity and adsorption intensity, respectively. For a good adsorbent, the values of $n$ ranged between 1 and 10. It is evident from Table 3 that the ' $n$ ' values ranged between 1.335 and 2.024 with a regression coefficient of 0.93 to 0.98 , indicating the strong interaction of $\mathrm{U}(\mathrm{vI})$ ions with the adsorbent.

\subsection{Thermodynamic studies}

The commonly used thermodynamic parameters, such as $\Delta G^{0}$, $\Delta H^{0}$ and $\Delta S^{0}$, were calculated from the adsorption data. ${ }^{40}$ Initially, $K_{\mathrm{c}}$, the equilibrium constant, was determined by eqn (10)

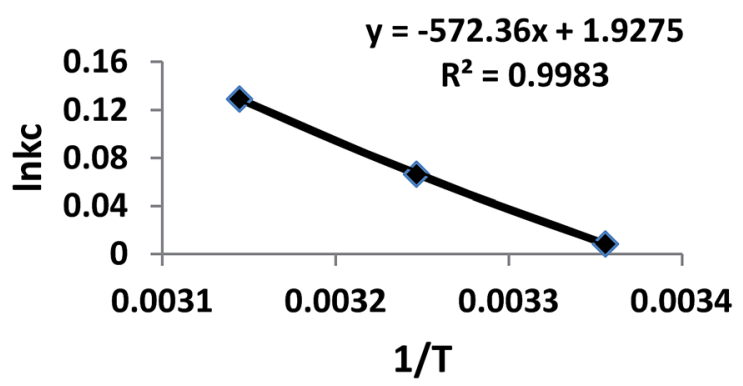

Fig. 6 Thermodynamic studies of ACF-Sal and U(vI) systems. 
Table 4 Thermodynamic parameters

\begin{tabular}{llllll}
\hline & $\begin{array}{l}C_{\mathrm{e}} \\
(\mathrm{K} \mathrm{L})\end{array}$ & $K_{\mathrm{c}}$ & $\begin{array}{l}\Delta G \\
\left(\mathrm{~kJ} \mathrm{~mol}^{-1}\right)\end{array}$ & $\begin{array}{l}\Delta S \\
\left(\mathrm{~J} \mathrm{~mol}^{-1}\right)\end{array}$ & $\begin{array}{l}\Delta H \\
{\left[\mathrm{~kJ}\left(\mathrm{~mol}^{-1} \mathrm{~K}^{-1}\right)\right]}\end{array}$ \\
\hline 298 & 0.2476 & 1.0192 & -0.0472 & & \\
308 & 0.2309 & 1.1649 & -0.3909 & 4.439 & 10.96 \\
318 & 0.2131 & 1.3463 & -0.7863 & &
\end{tabular}

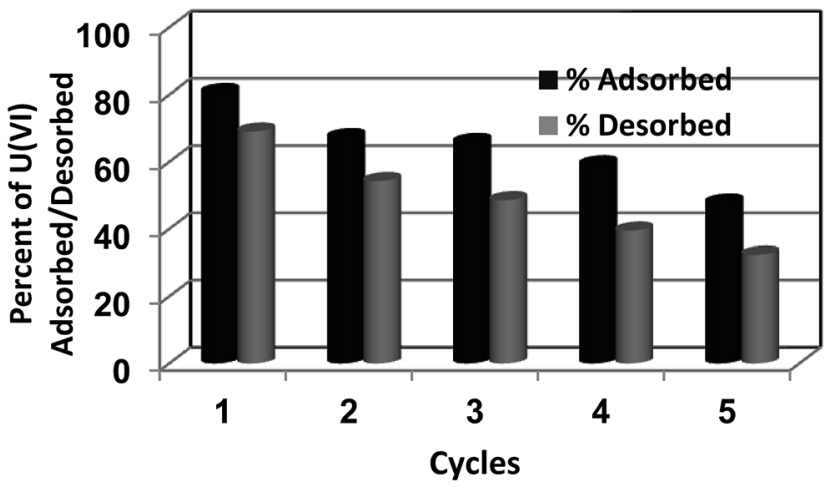

Fig. 7 Recyclability studies.

$$
K_{\mathrm{c}}=\frac{C_{\mathrm{A}}}{C_{\mathrm{e}}}
$$

where $C_{\mathrm{A}}\left(\mathrm{g} \mathrm{L}^{-1}\right)$ is the concentration of solute in the aqueous phase and $C_{\mathrm{e}}$ is the equilibrium concentration $\left(\mathrm{g} \mathrm{L}^{-1}\right) . \Delta G^{0}$ was calculated using the following equation:

$$
\Delta G^{0}=-R T \ln K_{\mathrm{c}}
$$

where $R$ is the gas constant and $T$ is the temperature in Kelvin. Using the Van't Hoff eqn (12) the value of $\Delta S$ and $\Delta H$ was determined:

$$
\log K_{\mathrm{c}}=\frac{\Delta S^{0}}{2.303}-\frac{\Delta H^{0}}{2.303 R T}
$$

Based on the above-calculated data, a linear plot of $\ln K_{\mathrm{c}} v s .1 / T$ was drawn for the U(v) and ACF-Sal system (Fig. 6). Using these plots, $\Delta S^{0}$ and $\Delta H^{0}$ were determined from the intercept and slope, respectively. The data obtained are presented in Table 4 . The negative free energy values indicate the spontaneity and feasibility of the process, while the positive $\Delta H^{0}$ values indicate the endothermic nature of the process. Furthermore, positive values of the entropy $\left(\Delta S^{0}\right)$ of adsorption could be attributed to metal ion dehydration due to surface sorption on ACF-Sal.

\subsection{Recyclability studies}

Uranium desorption studies were conducted after the sorption of U(vI) using ACF-Sal as a sorbent. The conditions for adsorption were maintained as prescribed in Sec 2.4. After the adsorption of $\mathrm{U}(\mathrm{vI})$ ions, the sorbents were filtered, washed with water, and $0.1 \mathrm{M} \mathrm{H}_{3} \mathrm{PO}_{4}$ was used as a desorbent. The sorptiondesorption cycle was repeated for 5 cycles. The amount of $\mathrm{U}(\mathrm{vI})$
Table 5 Effect of competing cations on sorption of U(VI) by ACF-Sal

\begin{tabular}{lll}
\hline & $q_{\text {mix }} / q_{0}$ & \\
\cline { 2 - 3 } Cations & $100 \mathrm{mg} \mathrm{L}^{-1}$ & $200 \mathrm{mg} \mathrm{L}^{-1}$ \\
\hline $\mathrm{Ni}^{2+}$ & 0.91 & 0.89 \\
$\mathrm{Cd}^{2+}$ & 0.82 & 0.76 \\
$\mathrm{Ca}^{2+}$ & 0.97 & 0.94 \\
$\mathrm{~Pb}^{2+}$ & 0.90 & 0.86 \\
$\mathrm{Cu}^{2+}$ & 0.99 & 0.92 \\
$\mathrm{Mn}^{2+}$ & 1.00 & 1.00
\end{tabular}

Table 6 Effect of competing anions on sorption of U(VI) by ACF-Sal

\begin{tabular}{lc}
\hline Anions $(0.1 \mathrm{M})$ & $q_{\text {mix }} / q_{0}$ \\
\hline Sulphate & 0.97 \\
Chloride & 0.93 \\
Nitrate & 1.00 \\
Phosphate & 1.10
\end{tabular}

\begin{tabular}{|c|c|}
\hline Complex & $K_{\text {ass }}\left[\mathrm{M}^{-1}\right]$ \\
\hline Sal- $\mathrm{UO}_{2}-\mathrm{Cl}^{-}$ & $4.5 \times 10^{2}$ \\
\hline Sal- $\mathrm{UO}_{2}-\mathrm{NO}_{2}{ }^{-}$ & $3.1 \times 10^{2}$ \\
\hline Sal- $\mathrm{UO}_{2}-\mathrm{HSO}_{4}^{-}$ & $5.0 \times 10^{1}$ \\
\hline Sal- $\mathrm{UO}_{2}-\mathrm{H}_{2} \mathrm{PO}_{4}^{-}$ & $1.1 \times 10^{4}$ \\
\hline
\end{tabular}

Table 7 The experimental stability constants $\left(K_{\text {ass }}\right)$ for the uranyl salophene (US1) complexation with anions ${ }^{a}$

${ }^{a}$ Adapted from ref Stauthammer, W. Ph.D. Thesis, University of Twente, The Netherlands, 1994.

adsorbed by ACF-Sal for five consecutive sorption-desorption cycles are depicted in Fig. 7. It is evident from the figure that around a $20 \%$ and $40 \%$ decrease in U(vI) uptake was observed at the end of the $3^{\text {rd }}$ and $5^{\text {th }}$ cycle, respectively. A similar result has been reported using ordered mesoporous carbon as an adsorbent. ${ }^{11}$

\subsection{Effect of competing ions}

Uranium sorption by ACF-Sal in the presence of other cations and anions was studied. Initially, $100 \mathrm{ppm}$ of $\mathrm{U}(\mathrm{vI})$ was spiked with known concentrations of anions/cations and $\mathrm{pH}$ was adjusted to 6 and equilibrated for $3 \mathrm{~h}$. After equilibration, the solution was filtered and the amount of $\mathrm{U}(\mathrm{vI})$ adsorbed was analyzed using an ICP-MS instrument. The effect of these ions on the sorption process may be represented by the ratio of adsorption capacity in the presence of interfering ion $\left(q_{\text {mix }}\right)$ and without interfering ion $\left(q_{0}\right)$, as shown below. ${ }^{41}$

$q_{\text {mix }} / q_{0}>1$, increased adsorption in the presence of other interfering ions; $q_{\text {mix }} / q_{0}=1$, adsorption is not influenced in the presence of other interfering ions; $q_{\text {mix }} / q_{0}<1$, adsorption is suppressed in the presence of other interfering ions.

The effect of cations and anions on the sorption capacity of ACF-Sal is detailed in Tables 5 and 6, respectively. The order of interfering effect of the various cations tested is $\mathrm{Cd}^{2+}>\mathrm{Ni}^{2+}>\mathrm{Pb}^{2+}$ 


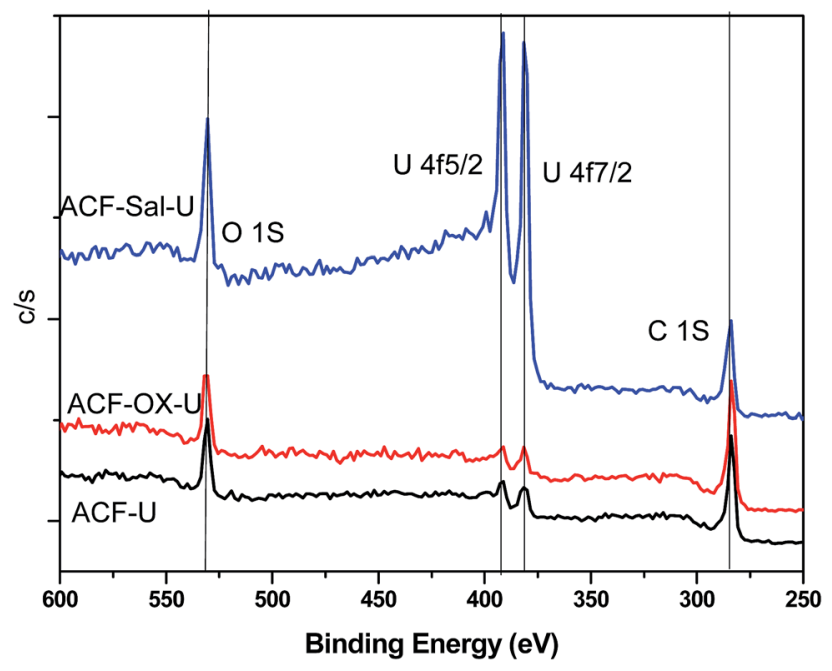

Fig. 8 Uranium loaded XPS wide scans of ACF, ACF-OX and ACF-Sal.

Table 8 Binding energies (eV) of ACF, ACF-OX and ACF-Sal after uranium adsorption

\begin{tabular}{lcclllc}
\hline Type & $\mathrm{C} 1 \mathrm{~s}$ & $\mathrm{O} 1 \mathrm{~s}$ & $\mathrm{~N} \mathrm{1s}$ & ${\mathrm{U} 4 \mathrm{f}_{5 / 2}}$ & ${\mathrm{U} 4 \mathrm{f}_{7 / 2}}$ & $\begin{array}{l}\text { Splitting } \\
\text { values }\end{array}$ \\
\hline ACF-U & 284.35 & 530.80 & - & 390.87 & 381.00 & 9.87 \\
ACF-OX-U & 284.48 & 530.43 & - & 391.57 & 381.25 & 10.32 \\
ACF-Sal-U & 285.30 & 531.35 & 398.53 & 391.67 & 381.30 & 10.37
\end{tabular}

$>\mathrm{Cu}^{2+}>\mathrm{Ca}^{2+} \ggg \mathrm{Mn}^{2+}$. An increased interfering effect was observed for $\mathrm{Cd}^{2+}, \mathrm{Ni}^{2+}$ and $\mathrm{Pb}^{2+}$ ions. This could be attributed to their complexation with salophen ligand and non-availability of these complexing sites for $\mathrm{U}(\mathrm{vI})$ sorption. Among the various anions tested, it is interesting to observe that a slight increase of the sorption of $\mathrm{U}(\mathrm{vI})$ ions is observed in the presence of phosphate ions. Coordination around uranium is pentagonal bipyramidal with the four donor atoms of the salophen ligand occupying the equatorial plane and the uranyl oxygen atoms in the axial positions. The fifth equatorial site of the metal remains available for coordination by an additional group, either an anion or a neutral molecule. Due to the high affinity of $\mathrm{UO}_{2}{ }^{2+}$ to phosphate anions, ${ }^{42}$ the stability constants of $\mathrm{Sal}-\mathrm{UO}_{2}-\mathrm{H}_{2} \mathrm{PO}_{4}{ }^{-}$is larger than other anions $\left(\mathrm{Cl}^{-}, \mathrm{SO}_{4}{ }^{2-}, \mathrm{NO}_{3}{ }^{-}\right)$tested and the data is furnished in Table 7. This explains the increased uptake of $\mathrm{U}(\mathrm{vI})$ by ACF-Sal in the presence of phosphate ions. Furthermore, it should be noted that when desorption studies were conducted with $0.1 \mathrm{M} \mathrm{H}_{3} \mathrm{PO}_{4}$, around $85 \%$ of $\mathrm{U}(\mathrm{vI})$ was found to be desorbed (Sec 3.6). This is probably because the acidity of the desorbing solution is around $\mathrm{pH} 1$ and at this acidity, the $\mathrm{U}(\mathrm{vI})$ salophen complex is unstable and uranyl-phosphate complexation takes place, which results in leaching of $\mathrm{U}(\mathrm{vr})$ from the sorbent surface.

\subsection{XPS evaluation}

In order to study the sorption of $\mathrm{U}(\mathrm{vI})$ onto ACF, ACF-OX and ACF-Sal, XPS spectra were recorded after U(vI) loading. The O 1s,
$\mathrm{C} 1 \mathrm{~s}$, and $\mathrm{U} 4 \mathrm{f}$ of the sorbents are demonstrated in Fig. 8. In the survey spectra (Fig. 8), the characteristic doublet peaks of $U 4 f_{5 / 2}$ and $U \mathrm{f}_{7 / 2}$ were observed for all the loaded sorbents. The binding energies of the various peaks and the splitting values of uranium peaks are depicted in Table 8. The peak positions of $\mathrm{U}(\mathrm{vI})$ adsorbed on ACF-Sal shifted to relative high binding energies as compared to those of $\mathrm{U}(\mathrm{vI})$ adsorbed onto ACF and ACF-OX, which could be attributed to the stronger interaction of $\mathrm{U}(\mathrm{vI})$ with ACF-Sal compared to ACF and ACF-OX. A similar observation was observed by other researchers on uranyl sorption onto chitosan modified CNTs. ${ }^{43}$ Upon further comparison of the splitting values of $4 \mathrm{f}_{5 / 2}$ and $4 \mathrm{f}_{7 / 2}$ peaks of $\mathrm{U}(\mathrm{vI})$ ions onto ACF, ACF-OX, and ACF-Sal, an increasing trend is observed, which could be attributed to stronger interaction of $\mathrm{U}(\mathrm{vI})$ with salophen ligand.

In order to further probe the mechanism of U(vI) sorption on to ACF-Sal at the molecular level, the XPS spectra of survey and high resolution scans for $\mathrm{O} 1 \mathrm{~s}, \mathrm{~N} 1 \mathrm{~s}$, and $\mathrm{U} 4 \mathrm{f}$ on ACF-Sal were recorded. The $\mathrm{O} 1 \mathrm{~s}, \mathrm{~N} 1 \mathrm{~s}$, and $\mathrm{U} 4 \mathrm{f}$ of the ACF-Sal before and after $\mathrm{U}(\mathrm{vI})$ sorption (denoted as ACF-Sal-U) are demonstrated in Fig. 9. The peak fitting results of the $U 4 \mathrm{f}, \mathrm{O} 1 \mathrm{~s}$, and $\mathrm{N} 1 \mathrm{~s}$ before and after $\mathrm{U}(\mathrm{vI})$ sorption on ACF-Sal are listed in Table 9. As shown in Fig. 9e, the $U \mathrm{Uf}_{7 / 2}$ spectrum was resolved into two peaks: the peak at $379.5 \mathrm{eV}$ corresponded to the free uranyl adsorbed on ACF-Sal, and the peak at $381.08 \mathrm{eV}$ was attributed to covalent bond of azomethine $\mathrm{N}-\mathrm{U}(\mathrm{vr}) .{ }^{44} \mathrm{Fig}$. $9 \mathrm{~b}$ shows that the $\mathrm{O}$ 1s spectra could be resolved into three main peaks, occurring at $530.54,531.94$ and $532.77 \mathrm{eV}$ corresponding to $\mathrm{O}=\mathrm{C}, \mathrm{C}-\mathrm{O}-\mathrm{C}$ and $\mathrm{H}-\mathrm{O}-\mathrm{H}$ bonds ${ }^{45}$ respectively. Thus, XPS studies have been used to study the efficient anchoring of salophen ligand onto the CNT back bone. ${ }^{46}$ After U(vI) sorption (Fig. 9d) four different peaks occurred at $529.47,529.97,530.53,531.85 \mathrm{eV}$. An additional peak after $\mathrm{U}(\mathrm{vI})$ sorption could be attributed to the presence of the $\mathrm{U}=\mathrm{O}$ bond. ${ }^{46,47}$ Furthermore, the shift in the binding energies of $\mathrm{O} 1 \mathrm{~s}$ before and after $\mathrm{U}(\mathrm{vI})$ loading indicated that U(vi) sorption onto ACF-Sal occurred by the complexation of oxygen-containing functional groups. The calculation of the content of elements on the surface of ACFs by the area of each element showed that the weight content of $\mathrm{N}$ is about $3.2 \%$, indicating the presence of Schiff-base groups. Fig. 9a and c show the core level $\mathrm{N}$ 1s of ACF-Sal before and after U(vI) sorption, respectively. The $\mathrm{N}$ 1s spectrum was resolved into two individual component peaks at 395.5 and $402.0 \mathrm{eV}^{48}$ After uranyl sorption, the peaks shifted to higher binding energies due to the charge transfers occurring from nitrogen containing salophen ligand to $\mathrm{U}(\mathrm{vr})$ ions.

Thus, the results from XPS studies suggest that the salophen ligand is efficiently anchored onto the ACF surface and U(vI) complexation occurred with the tetradentate $\mathrm{N}(2) \mathrm{O}(2)$ donors derived from the phenolic oxygen and azomethine nitrogen of the saplohen ligand.

\subsection{Mechanism of interaction}

Adsorption of U(vI) onto ACF and ACF-OX might be attributed to both ion exchange and electron donating acceptor complexation reactions at the surface sites. At $\mathrm{pH}$ 6.0, where in the 

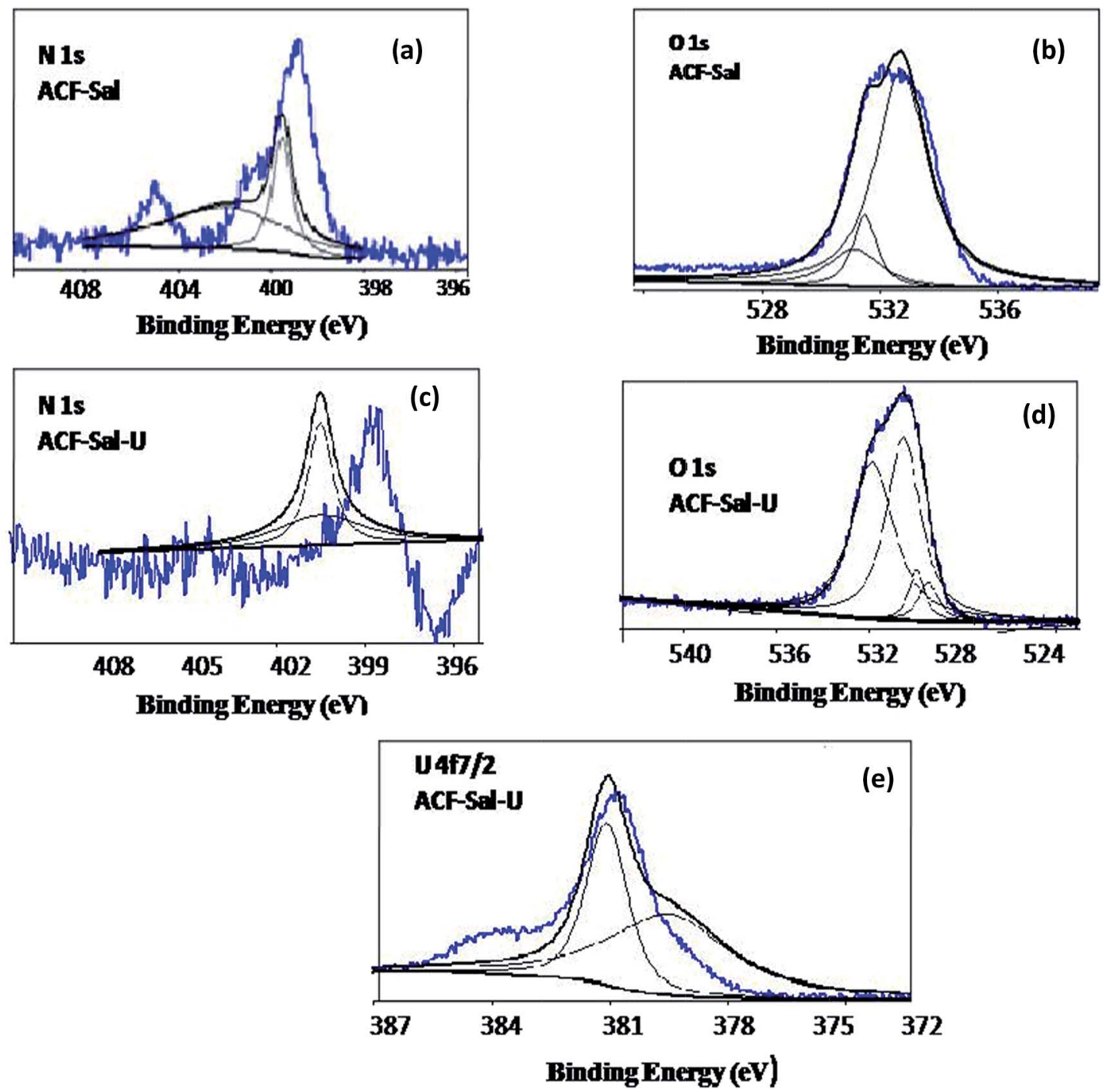

Fig. 9 Curve fitted high resolution XPS scans of ACF-Sal for (a) O 1s, (b) N 1s before $U(v)$ loading and (c) O 1s, (d) N 1s and U 4f (e) after U(vi) loading.

Table 9 Core level binding energies of ACF-Sal and U(VI) loaded ACF-Sal systems

\begin{tabular}{|c|c|c|c|c|c|c|}
\hline Core levels & ACF-Sal & & & ACF-Sal-U & & \\
\hline \multirow[t]{2}{*}{$\mathrm{N} 1 \mathrm{~s}$} & Binding energy $(\mathrm{eV})$ & FWHW (eV) & Area & Binding energy $(\mathrm{eV})$ & FWHW (eV) & Area \\
\hline & 395.5 & 1.00 & 143.38 & 400.50 & 3.520 & 82.12 \\
\hline \multirow[t]{3}{*}{$\mathrm{O} 1 \mathrm{~s}$} & 530.54 & 1.69 & 2326.78 & 531.85 & 2.230 & 2154.16 \\
\hline & 531.94 & 1.37 & 982.99 & 530.53 & 1.766 & 2002.55 \\
\hline & 532.77 & 1.51 & 186.71 & 529.47 & 1.000 & 243.86 \\
\hline & - & - & - & 381.08 & 1.263 & 735.34 \\
\hline
\end{tabular}

maximum removal of $\mathrm{U}(\mathrm{vI})$ is observed (Fig. 3), 95\% of the uranyl ions exist as $\left(\mathrm{UO}_{2}\right)_{3}(\mathrm{OH})_{5}{ }^{+}$species and few as $\mathrm{UO}_{2}{ }^{2+} \cdot{ }^{49}$ It is well known that at $\mathrm{pH}$ 6.0, the carboxyl groups are deprotonated and there exists a strong complexation between the hydrolyzed uranyl ions $\left[\left(\mathrm{UO}_{2}\right)_{3}(\mathrm{OH})_{5}^{+}\right]$and carboxyl groups. The FTIR spectra of ACF, ACF-OX and ACF-Sal before and after loading with $\mathrm{U}(\mathrm{vI})$ are shown in Fig. 10. It is evident from the spectra that after U(vI) loading in ACF (Fig. 10a), the hydroxyl peak shifts from $3437 \mathrm{~cm}^{-1}$ to $3418 \mathrm{~cm}^{-1}$, which confirms the involvement of $\mathrm{OH}$ group and a sharp peak at $920 \mathrm{~cm}^{-1}$ confirms the $v_{3}$ band of uranyl ions. ${ }^{50,51}$ In U(vi) loaded ACF-OX, the shifting of the carbonyl stretching peak from 1721 to $1715 \mathrm{~cm}^{-1}$ is observed. In 

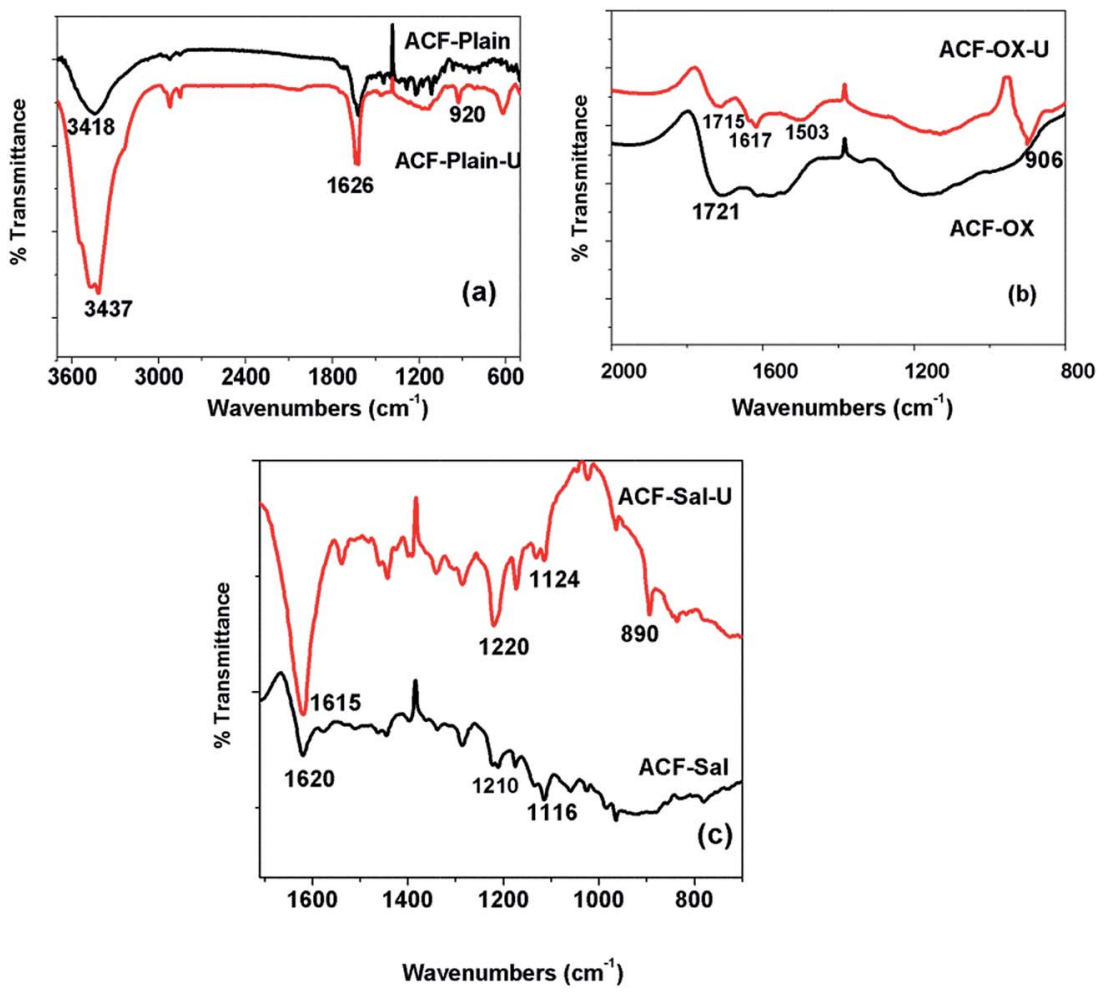

Fig. 10 FTIR spectra of (a) ACF (b) ACF-OX and (c) ACF-Sal before and after loading uranyl ions.

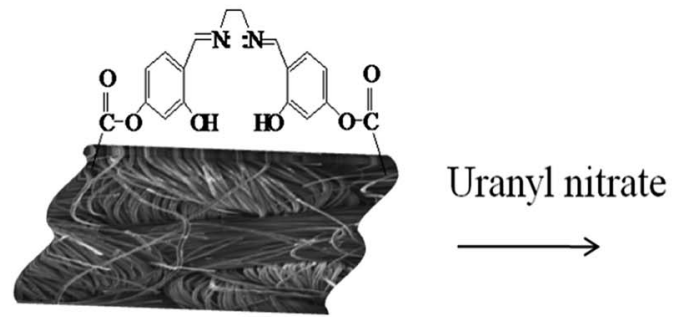

ACF-Sal

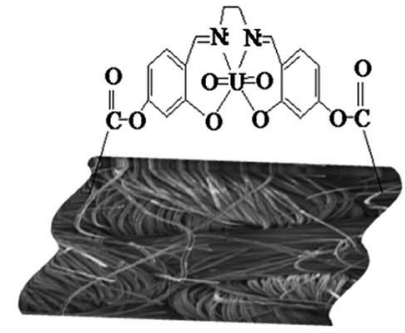

ACF-uranyl Salophen

Scheme 2 Schematic of complexation of U(VI) with ACF-salophen.

addition, a uranyl band appears at $906 \mathrm{~cm}^{-1}$, which is a characteristic of the $v_{3}$ band of uranyl ions described earlier. Moreover, the $\mathrm{U}(\mathrm{vI})$ removal might be attributed to the electron donating acceptor (EDA) complexation between the de-localized $\pi$-electron of graphene layers of ACF and $\left(\mathrm{UO}_{2}\right)_{3}(\mathrm{OH})_{5}{ }^{+}$by dispersive forces. ${ }^{52}$

The main mechanism governing the sorption of $\mathrm{U}(\mathrm{vI})$ onto ACF-Sal is the complexation reaction occurring between the salophen ligand and the uranyl ions. After complexation with $\mathrm{U}(\mathrm{vI})$ (Fig. 10c), the environment of $\mathrm{C}=\mathrm{N}$ changes and a shift from 1620 to $1615 \mathrm{~cm}^{-1}$ is observed. Furthermore, the stretching vibrations of $-\mathrm{C}-\mathrm{O}$ and $\mathrm{C}-\mathrm{N}$ exhibited a slight upfield shift to $1220 \mathrm{~cm}^{-1}$ and $1124 \mathrm{~cm}^{-1}$, respectively, owing to the complexation. ${ }^{21}$ As observed in ACF and ACF-OX, a $v_{3}$ uranyl band appeared around $890 \mathrm{~cm}^{-1}$ for U(vI) loaded ACF-
Sal. The shifting of the frequencies of the uranyl band depends on the ligands present in the equatorial plane. In general, the asymmetrical uranyl stretching frequency ranges from $885 \mathrm{~cm}^{-1}$ to $899 \mathrm{~cm}^{-1}$ for uranyl complexes with Schiff base. ${ }^{53-57}$ This further confirms the complexation between $\mathrm{U}(\mathrm{vI})$ and salophen ligand.

Based on the discussions of the FTIR and XPS studies, a mechanism has been suggested in Scheme 2, depicting the complexation of uranium and salophen ligand.

\section{Conclusions}

Functionalized activated carbon fibres were prepared by oxidation and grafting salophen ligand. The prepared sorbent materials were characterized by various spectral techniques. The kinetics followed a pseudo second order model and 
maximum removal of $\mathrm{U}(\mathrm{vI})$ was found at $\mathrm{pH}$ 6. The experimental data obtained were analyzed by various isotherms, including Langmuir and Freundlich. The adsorption capacities of the functionalized ACFs were in the order of ACF-Sal > ACF-OX > ACF. The observed high capacity (142.8 $\mathrm{mg} \mathrm{g}^{-1}$ for ACF-Sal by Langmuir and $305.09 \mathrm{mg} \mathrm{g}^{-1}$ by two site Langmuir model) could be attributed to the bonding of $\mathrm{U}(\mathrm{vI})$ and the salophen ligand. The effect of other commonly occurring cations and anions on the sorption U(vi) by ACF-Sal was studied. Thermodynamic studies revealed the spontaneity of the reaction and the sorbent could be recycled for 5 sorption-desorption cycles. From the FTIR and XPS studies a suitable mechanism for sorption has also been proposed.

\section{Acknowledgements}

Authors thank the funding received from the Board of Research in Nuclear Sciences, Department of Atomic Energy, Mumbai, India (Ref. no. 2013/36/57-BRNS/2482) to carry out this study.

\section{Notes and references}

1 G. M. Naja and B. Volesky, Toxicity and sources of $\mathrm{Pb}, \mathrm{Cd}, \mathrm{Hg}$, $\mathrm{Cr}$, As and radionuclides in the environment, CRC Press, Taylor \& Francis Group, USA, 2009, p. 16.

2 WHO, Guidelines for Drinking Water Quality, Geneva, 2nd edn, 1998, p. 283.

3 A. Kilincarslan and S. Akyil, J. Radioanal. Nucl. Chem., 2005, 264, 541.

4 P. D. Bhalara, D. Punetha and K. Balasubramanian, J. Environ. Chem. Eng., 2014, 2, 1621.

5 P. Swain, C. Mallika, R. Srinivasan, U. K. Mudali and R. Natarajan, J. Radioanal. Nucl. Chem., 2013, 298, 781.

6 A. M. A. Morsy and A. E. M. Hussein, J. Radioanal. Nucl. Chem., 2011, 288, 341.

7 M. Caccin, F. Giacobbo, M. Da Ros, L. Besozzi and M. Mariani, J. Radioanal. Nucl. Chem., 2013, 297, 9.

8 Y. Sun, S. Yang, G. Sheng, Z. Gua and X. Wang, J. Environ. Radioact., 2012, 105, 40.

9 A. Schierz and H. Zanker, Environ. Pollut., 2009, 157, 1088.

10 D. D. Shao, Z. Q. Jiang, X. K. Wang, J. X. Li and Y. D. Meng, J. Phys. Chem., 2009, 113, 860.

11 B.-W. Nie, Z.-B. Zhang, X.-H. Cao, Y.-H. Liu and P. Liang, J. Radioanal. Nucl. Chem., 2012, 295, 663.

12 V. Gaur, A. Sharma and N. Verma, Chem. Eng. Process., 2006, 45, 1-13.

13 B. M. Babić, S. K. Milonjić, M. J. Polovina, S. Čupić and B. V. Kaludjerović, Carbon, 2002, 40, 1109.

14 R. Leyva-Ramos, M. S. Berber-Mendoza, J. Salazar-Rabago, R. M. Guerrero-Coronado and J. Mendoza-Barron, Adsorption, 2011, 17, 515.

15 J. R. Rangel-Mendez and M. Streat, Water Res., 2002, 36, 1244.

16 M. A. Alvarez-Merino, V. Lopez-Ramon and C. MorenoCastilla, J. Colloid Interface Sci., 2005, 288, 335.
17 M. S. Berber-Mendoza, R. Leyva-Ramos, F. J. CerinoCordoba, J. Mendoza-Barron, H. J. Amezquita Garcia and J. V. Flores-Cano, Water, Air, Soil Pollut., 2013, 224, 1604.

18 X. Zhou, H. Yi, X. Tang, H. Deng and H. Liu, Chem. Eng. J., 2012, 200-202, 399.

19 M. Bikshapathi, S. Mandal, G. N. Mathur, A. Sharma and N. Verma, Ind. Eng. Chem. Res., 2011, 50, 13092-13104.

20 C.-H. Jung, H.-Y. Lee, J.-K. Moon, H.-J. Won and Y.-G. Shul, J. Radioanal. Nucl. Chem., 2011, 287, 833.

21 M. Wu, L. Liao, M. Zhao, Y. Lin, X. Xiao and C. Nie, Anal. Chim. Acta, 2012, 729, 80.

22 J. L. Sessler, P. J. Melfi and G. D. Pantos, Coord. Chem. Rev., 2006, 250, 816.

23 M. Salavati-Niasari and M. Bazarganipour, Appl. Surf. Sci., 2008, 255, 2963-2970.

24 C.-C. Huang and Y.-J. Su, J. Hazard. Mater., 2010, 175, 477. 25 G. Wang, J. Liu, X. Wang, Z. Xie and N. Deng, J. Hazard. Mater., 2009, 168, 1053-1058.

26 M. Wang, J. Qiu, X. Tao, C. Wu, W. Cui, Q. Liu and S. Lu, J. Radioanal. Nucl. Chem., 2011, 288, 895.

27 S. Lagergren, K. Sven. Vetenskapsakad. Handl., 1898, 24, 1-39.

28 Y. S. Ho, D. A. J. Wase and C. F. Forster, Environ. Technol., 1996, 17, 71.

29 Y. S. Ho and G. McKay, Advances in Adsorption Separation Science and Technology, South China University of Technology Press, Guangzhou, 1997, pp. 257-263.

30 W. J. Weber and J. C. Morris, J. Sanit. Eng. Div., Am. Soc. Civ. Eng., 1963, 89, 31.

31 I. Langmuir, J. Am. Chem. Soc., 1918, 40, 1361.

32 G. Sposito, On the use of the Langmuir equation in the interpretation of "adsorption" phenomena: II. The "two surface” Langmuir equation, Soil Sci. Soc. Am. J., 1982, 46, 1147-1152.

33 Y. Jin, F. Liu, M. Tong and Y. Hou, J. Hazard. Mater., 2012, 227, 461.

34 D. Shao, Z. Jiang, X. Wang, J. Li and Y. Meng, J. Phys. Chem. $B, 2009,113,860$.

35 A. K. S. Deb, P. Ilaiyaraja, D. Ponraju and B. Venkatraman, J. Radioanal. Nucl. Chem., 2012, 291, 877.

36 Z.-J. Yi, J. Yao, J.-S. Xu, M.-S. Chen, W. Li, H.-L. Chen and F. Wang, J. Radioanal. Nucl. Chem., 2014, 301, 695.

37 P. S. Dubey, D. A. Dwivedi, M. Sillanpaa, Y.-N. Kwon and C. Lee, $R S C A d v ., 2014,4,46114$.

38 N. Sankararamakrishnan, A. Dixit, L. Iyengar and R. Sanghi, Bioresour. Technol., 2006, 97, 2377.

39 H. M. F. Freundlich, J. Phys. Chem., 1906, 57, 385.

40 P. Perrot, A to $Z$ of Thermodynamics, Oxford University Press, New York, 1998.

41 F. V. Pereira, L. V. A. Gurgel and L. F. Gil, J. Hazard. Mater., 2010, 176, 856.

42 M. Merdivan, M. B. Buchmeister and G. Bonn, Anal. Chim. Acta, 1999, 402, 91.

43 J.-H. Chen, D.-Q. Lu, B. Chen and P.-K. Ouyang, J. Radioanal. Nucl. Chem., 2013, 295, 2233.

44 W. Song, M. Liu, R. Hu, X. Tan and J. Li, J. Chem. Eng., 2014, 246, 268. 
45 M. Salavati-Niasari, F. Davar and M. Bazarganipour, Dalton Trans., 2010, 39, 7330.

46 S. Vanden Berghe, F. Miserque, T. Gouder, B. Gaudreau and M. Verwerft, J. Nucl. Mater., 2001, 294, 168.

47 S. Chen, J. Hong, H. Yang and J. Yang, J. Environ. Radioact., 2013, 126, 253.

48 R. J. J. Jansen and H. van Bekkum, Carbon, 1995, 33, 1021.

49 E. Guibal, C. Roulph and P. Le Cloirec, Water Res., 1992, 26, 1139.

50 R. L. Frost, Spectrochim. Acta, Part A, 2006, 64, 308.

51 M. Tsezos and B. Volesky, Biotechnol. Bioeng., 1982, 24, 385.
52 S. M. Yakout, S. S. Metwally and T. El-Zakla, Appl. Surf. Sci., 2013, 280, 745.

53 K. Mizuoka, S.-Y. Kim, M. Hasegawa, T. Hoshi, G. Uchiyama and Y. Ikeda, Inorg. Chem., 2003, 42, 1031.

54 K. Mizuoka, S. Tsushima, M. Hasegawa, T. Hoshi and Y. Ikeda, Inorg. Chem., 2005, 44, 6211.

55 K. Mizuoka and Y. Ikeda, Radiochim. Acta, 2004, 92, 631.

56 L. Cattalini, S. Degetto, M. Vidali and P. A. Vigato, Inorg. Chim. Acta, 1972, 6, 173.

57 E. M. Nour, A. A. Taha and I. S. Alnaimi, Inorg. Chim. Acta, 1988, 141, 139. 